OPEN ACCESS

Edited by:

Ondrej Slaby,

Central European Institute of

Technology (CEITEC), Czechia

Reviewed by:

Pawel Buczkowicz,

Independent researcher, Toronto,

Canada

Ranran Zhang,

Aspirus Riverview Hospital,

United States

*Correspondence:

Weiqin Chang

weiqinchang@126.com

Specialty section:

This article was submitted to

Cancer Genetics,

a section of the journal

Frontiers in Oncology

Received: 29 August 2019

Accepted: 13 May 2020

Published: 11 June 2020

Citation:

Peng $X$, Zhang $K, M a L, X U J$ and

Chang W (2020) The Role of Long

Non-Coding RNAs in Thyroid Cancer.

Front. Oncol. 10:941

doi: 10.3389/fonc.2020.00941

\section{The Role of Long Non-Coding RNAs in Thyroid Cancer}

\author{
Xuejiao Peng ${ }^{1}$, Kun Zhang ${ }^{2}$, Li Ma ${ }^{1}$, Junfeng $\mathrm{Xu}^{1}$ and Weiqin Chang ${ }^{1 *}$ \\ ${ }^{1}$ Department of Thyroid Surgery, Second Affiliated Hospital of Jilin University, Changchun, China, ${ }^{2}$ Medical Research Center, \\ Second Affiliated Hospital of Jilin University, Changchun, China
}

Thyroid cancer, the most common endocrine malignancy, has become the most commonly diagnosed malignant solid tumor. Moreover, some cases have poor prognosis, and the survival period is only 3-5 months. Long noncoding RNAs (IncRNAs) are a group of functional RNA molecules more than 200 nucleotides in length that lack the ability to encode protein but participate in all aspects of gene regulation. Functionally, many IncRNAs play essential roles in epigenetic regulation at transcriptional and post-transcriptional levels via various molecular mechanisms. Recent studies have discovered important roles for IncRNAs during the complex process of carcinogenesis in thyroid cancer. In this review, we focus on IncRNAs dysregulated in thyroid cancer and summarize recently reported associations between IncRNAs and thyroid cancer in order to demonstrate the significant value of IncRNAs in diagnosis and treatment.

Keywords: thyroid cancer, molecular mechanism, biomarker, tumorigenesis, long non-coding RNAs

\section{INTRODUCTION}

Thyroid cancer is the most common endocrine tumor. Its incidence is reportedly seventh highest among female malignancies in developed countries and ninth highest among female malignancies in developing countries (1). In recent years, the incidence of thyroid cancer worldwide has increased significantly, which may be attributed to earlier screening. Age-standardized statistics show that the global incidence of thyroid cancer in 2016 was 2.2/100,000 men per year and $4.4 / 100,000$ women per year, and the incidence increased by $50 \%$ from 2006 to 2016 , the fastest increase for any malignant solid tumor (2). As a female-prone tumor, thyroid cancer ranks first among malignant tumors affecting the female population in various countries and regions. Research shows that by 2019, thyroid cancer will rank third among such tumors (3). Although most thyroid cancers can be effectively controlled by surgery, endocrine inhibition therapy, and iodine radiation, mortality associated with advanced thyroid cancer and iodine-refractory thyroid cancer has not decreased. Understanding the pathogenesis of thyroid cancer, and finding biomarkers for its early diagnosis and effective treatment are current focal points of research.

Studies have shown that only $2 \%$ of the genes of many mammals are involved in the protein translation process, while the remaining $98 \%$ of RNAs are only involved at the transcriptional level and are called "non-coding RNAs" (ncRNAs). Based on their molecular sizes, ncRNAs are classified as short ncRNAs or long ncRNAs (lncRNAs). Short ncRNAs include miRNAs, tRNAs, interfering small RNAs (siRNAs), RNAs that interact with Piwi proteins (PiRNAs), and certain ribosomal RNAs. IncRNAs have broader research prospects and are a current research focus. lncRNAs, as ncRNAs longer than $200 \mathrm{nt}$, are not translated to proteins due to their lack of open 
reading frames. Although lncRNAs are not involved in protein transcription, they can regulate gene expression at multiple levels and are related to tumorigenesis. In recent years, with the emergence of next-generation sequencing, third-generation sequencing, RNA-Seq, RIP-Seq, and RNA arrays, more and more lncRNAs have been discovered. Recent reports and ongoing studies have found that many lncRNAs are closely related to thyroid cancer. This article discusses the recent research progress on IncRNAs and papillary thyroid cancer (PTC) by reviewing the latest research reports.

\section{FUNCTIONAL LNCRNAS INVOLVED IN THYROID CANCER}

An increasing number of studies have confirmed that differential expression of IncRNAs is closely related to the biological behavior of thyroid cancer. Yang et al. (4) compared the expression of IncRNAs in three groups of thyroid cancer tissues and paracancerous tissues by microarray analysis and found that there were 675 differentially expressed lncRNAs in PTC, of which 312 were upregulated and 363 downregulated. In addition, some studies have used certain IncRNAs to establish biomarker systems for detecting recurrence and prognosis in patients with PTC (5). However, the value of IncRNAs in the diagnosis, treatment, and prognosis of thyroid cancer warrants further research.

Thus far, many lncRNAs have been found to be closely associated with the occurrence and progression of thyroid cancer. Additionally, the studied mechanisms of action of lncRNAs in thyroid cancer include the following: lncRNAmiRNA-protein, IncRNA(-miRNA)-target genes, epigenetics, and signaling pathways. Representative lncRNAs include NEAT1, HOTAIR, PTCSC2, IncRNA TNRC6C-AS1, GAS8-AS1, PTCSC3, MEG3, BANCR, PVT1, SPRY4-IT1, GAS5, H19, CASC2, and MALAT1.

\section{IncRNA-miRNA-Protein}

This is currently the most common mechanism of action associated with lncRNAs, which are regarded as among the most important competing endogenous RNAs (ceRNAs) and participate in the regulation of gene networks by acting on target genes or proteins. IncRNAs promote proliferation of thyroid cancer cells by competitively inhibiting miRNAs through regulation of downstream proteins highly expressed in thyroid cancer tissues.

\footnotetext{
Abbreviations: ATAD2, ATPase family AAA domain-containing 2; CCND2, cyclin D2; ceRNA, competing endogenous RNA; EMT, epithelial to mesenchymal transition; $\mathrm{EZH} 2$, zeste homolog 2; FN1, fibronectin 1; FNA, fine-needle aspiration; FOXE1, forkhead box E1; GEO, Gene Expression Omnibus database; IGF1R, growth factor 1 receptor; IRS1, insulin receptor substrate 1; IncRNA, long non-coding RNA; LNM, lymph node metastasis; MYH9, myosin-9; PI3k/AKT, phosphatidylinositol 3-kinase/AKT; PTC, papillary thyroid cancer;; Rac1, rho GTPase1; SNP, single nucleotide polymorphism; TAM, tumor-associated macrophages; TCGA, The Cancer Genome Atlas; TGF, transforming growth factor; TSH, thyroid-stimulating hormone; TSHR, thyroid-stimulating hormone receptor; UNC5B, UNC-5 netrin Receptor B; VEGF, vascular endothelial growth factor.
}

\section{Neat1}

lncRNA-rich nuclear-rich transcript 1 (NEAT1), located on chromosome 11q13.1, was discovered by Hutchinson et al. (6). NEAT1 reportedly acts as a ceRNA in tumorigenesis (7-12). There is increasing evidence that $\operatorname{lncRNAs}$ act as molecular sponges in many malignancies (13). NEAT1 is overexpressed in thyroid cancer tissues and cells compared to levels in normal thyroid tissues and cells. Highly expressed NEAT1 reportedly promotes $\beta$-catenin expression by interacting with miR-214. $\beta$ catenin is a direct target of miR-214 and participates in the malignant behavior of NEAT1-induced thyroid cancer (14). Zhang et al. (15) confirmed that NEAT1 is upregulated in thyroid carcinoma, and that its upregulation can inhibit the action of miRNA-129-5p and upregulate kallikrein-related peptidase 7 (KLK7) expression. As the seventh member of the serine protease family, KLK is increasingly found to be overexpressed in human cancers and facilitates cancer metastasis through degradation of cell junction proteins (15). Its dysregulation is related to tumorigenesis in ovarian, breast and cervical cancers, and melanoma. Overexpression of KLK7 is also closely related to poor prognosis in thyroid cancer. NEAT1 has two isoforms: NEAT1_1 $(3.7 \mathrm{~kb})$ and NEAT1_2 $(23 \mathrm{~kb})$. As an oncogene, NEAT1_2 is upregulated in thyroid cancer and is linked to tumor size and TNM stage. Sun et al. (16) reported that NEAT1_2 can regulate the expression of ATPase family AAA domain-containing 2 (ATAD2) by downregulating miR-106b-5p in papillary thyroid cancer. The study found that ATAD2 is abnormally expressed in hepatocellular carcinoma, prostate cancer, lung cancer, ovarian cancer, and cervical cancer, and its expression level is associated with tumor stage, histological grade, and lymph node metastasis (17). NEAT-2-targeted therapy may become a treatment option for thyroid cancer in the future.

Typically, postoperative radioactive iodine (RAI, 131I) treatment improves prognosis in some patients with thyroid cancer. However, Liu et al. (18) reported that NEAT1 suppressed the expression of miR-101-3p to upregulate fibronectin 1 (FN1), and ultimately invalidated the effect of RAI treatment. Additionally, overexpression of FN1 promotes activation of the PI3K/AKT signaling pathway, leading to RAI resistance in PTC.

FN1, a basic component of the extracellular matrix, is a biomarker of the epithelial-mesenchymal transition (EMT), which is positively correlated with PTC lymph node metastasis (LNM) (19). Xia et al. (19) indicated that FN1 overexpression was associated with larger PTC tumor size, PTC LNM, and advanced pTNM stage, causing recurrence and affecting prognosis.

\section{Hotair}

HOX antisense intergenic RNA (HOTAIR) is a $2.2 \mathrm{~kb}$ RNA molecule expressed from the Hoxc cluster located in chromosome 12q13.3 and is among the best-studied lncRNAs in cancer. Overexpression of HOTAIR has been linked to poor prognosis and increased invasiveness in cancer (20), and to the invasion and migration of hepatocellular carcinoma and glioma $(21,22)$. Thus far, there have been relatively few studies on the relationship between HOTAIR and thyroid cancer. HOTAIR has been found to be significantly upregulated in thyroid carcinoma cells as well as thyroid cancer tissue samples and plasma. 
Moreover, higher expression levels of plasma HOTAIR were positively correlated with worse 5-year survival rates in patients with thyroid cancer (23). Additionally, in vitro experiments indicated that knocking down HOTAIR can significantly inhibit the growth and invasion of thyroid cancer cells. In a study by Di et al. (24), HOTAIR overexpression in thyroid cancer cells and tissue inhibited miRNA and cyclin D2 (CCND2) protein activation. Silencing HOTAIR expression inhibits thyroid cancer cell growth in vivo and in vitro. HOTAIR negatively regulates miR-1 by direct competitive binding to the miR-1 locus and participates in the regulation of thyroid cancer cell carcinogenesis. CCND2 belongs to the conserved cyclin family, which controls the cell cycle, and has been shown to be highly expressed in ovarian and testicular tumors. The HOTAIR/miR1-CCND2 axis may be a new direction for lncRNA and thyroid cancer research. There are also other hypotheses about the relationship between HOTAIR and thyroid cancer. Zhu et al. (25) reported that the HOTAIR rs920778T allele, a PTC risk allele, is associated with significantly increased HOTAIR expression. Some studies have explored the relationship between lncRNA and thyroid cancer using bioinformatics, constructing ceRNA regulatory networks using the Gene Expression Omnibus (GEO) database and the Cancer Genome Atlas (TCGA). Chen et al. (26) hypothesized that HOTAIR may be involved in the development of PTC by interrupting neuronal growth. A study based on the TCGA and GEO databases showed that HOTAIR overexpression in PTC is linked to tumor size, lymph node metastasis, and poor prognosis, and may play an oncogenic role through the Wnt pathway (27). The mechanism linking PTC and HOTAIR warrants further study, as the expression of HOTAIR in plasma is being considered a novel diagnostic biomarker in PTC.

\section{IncRNA TNRC6C-AS1}

lncRNA TNRC6C-AS1 acts as a ceRNA on miR-129-5p in thyroid cancer. Hou et al. (28) reported that TNRC6C-AS1 sponges miR-129-5p and regulates UNC-5 netrin receptor B (UNC5B) in thyroid cancer, influencing cell proliferation, migration, and invasion. UNC5B is a netrin-1-dependent receptor that participates in axonal migration and angiogenesis by binding to netrin-1, which exerts its function in tumor suppression. The role of UNC5B in other tumors has been confirmed (29), but its role in thyroid cancer has rarely been studied. Studies have also found that TNRC6C-AS1 is upregulated in PTC tissues and increases proliferation, migration, and invasion of TPC1 cells. The expression of TNRC6C-AS1 was negatively correlated with mRNA levels of its coding partner, TNRC6C in PTC tissues. The study also found that knockdown of TNRC6C-AS1 or overexpression of TNRC6C upregulated the expression of iodine metabolism genes, including NIS, TPO, TSHR, and pendrin (30). The TNRC6C-AS1-TNRC6C axis plays an important role in tumorigenesis, invasion, and iodine accumulation in PTC.

\section{PTCSC2}

Papillary thyroid cancer susceptibility candidate 2 (PTCSC2) is a 60-nucleotide lncRNA located on chromosome 9q22 (31) and is divided into two subtypes: folded and unfolded. A study involving 65 thyroid cancer tissues found that both folded and unfolded PTCSC2 were expressed at lower levels than in normal thyroid tissues. The locus on chromosome $9 q 22$ contains an SNP closely related to PTC risk (rs965513). The locus also includes the forkhead box E1 (FOXE1) gene associated with thyroid development and PTCSC2 (32). PTCSC2 may work synergistically with rs965513 to cause thyroid cancer. Another recent report found that myosin-9 (MYH9) acts as an lncRNAbinding protein that targets the FOXE1 promoter region through interaction with PTCSC2 and exerts its regulatory function in thyroid cancer via downstream pathways; this may be the molecular mechanism by which the gene and rs965513 act (33). At present, there have been few studies on the role of PTCSC2 in thyroid cancer, and more research is needed to determine their relationship.

\section{IncRNA(-miRNA)-Target Genes}

Some lncRNAs act directly on target genes, while others act indirectly through miRNAs. Some lncRNAs act on target genes through both direct and indirect pathways.

\section{GAS8-AS1}

GAS8 antisense RNA 1 (GAS8-AS1) is located in the second intron of GAS8 and transcribes a 994 nt ncRNA in the opposite orientation of GAS8, which is reported to be a novel tumor suppressor that affects tumor cell proliferation in PTC. GAS8AS1 was first reported in PTC by Pan et al. (34), but its regulatory mechanism is still unclear. Using whole exome sequencing, Pan et al. reported that GAS8-AS1 is the most frequently altered gene other than BRAF. Recently, IncRNA GAS8-AS1 was further studied by Zhang et al. (35), who reported that its expression was dramatically lower in the plasma compared with levels observed in benign nodule controls and normal goiter. This study also associated downregulation of GAS8-AS1 with LNM; thus GAS8-AS1 can be used as a biomarker for LNM prediction. In addition, Qin et al. (36) found that the relative expression of GAS8-AS1 was significantly reduced in four PTC cell lines compared to levels in normal thyroid cell lines; they also found that the role of GAS8-AS1 in thyroid cancer may be related to autophagic activity. ATG5 is a key autophagy-related gene (ATG) associated with malignancy. Overexpression of GAS8-AS1 upregulates ATG5 at mRNA and protein levels. Yuan et al. found that GAS8-AS1 affects autophagy and proliferation by regulating the expression of ATG5. Plasma levels of lncRNA GAS8-AS1 may be a promising biomarker for the diagnosis, prognosis, and treatment of thyroid cancer.

\section{PTCSC3}

PTCSC3 is an lncRNA on locus $14 \mathrm{q} 13.3$ and is highly thyroidspecific (37). Jendrzejewski et al. (37) performed an experimental study including 46 cases of PTC and paracancerous tissues and found that the expression of PTCSC3 in PTC tissues was significantly lower than that in adjacent normal thyroid tissues. Another study found that rs944289 was significantly correlated with benign and malignant thyroid tumors in Japanese patients (38). Additionally, the size of the thyroid tumor and the extrathyroidal invasion of the tumor were significantly correlated with the expression level of rs965513. S100A4 belongs 
to a large family of EF-hand domain calcium-binding proteins and has become a recognized marker of cancer metastasis in S100 transcripts. Overexpression of the S100A4 gene was first associated with the occurrence, development, and prognosis of breast cancer, gastric cancer, rectal cancer, lung cancer, melanoma, and other cancers (39-43). The same gene was later confirmed to be closely related to thyroid cancers other than medullary cancer. Jendrzejewski et al. (44) found that decreased expression of PTCSC 3 in PTC tissue can promote the overexpression of the S100A4 gene and the proliferation, invasion, and metastasis of thyroid cancer cells. Donato (45) found that the expression levels of vascular endothelial growth factor (VEGF) and matrix metalloproteinase-9 (MMP-9) were also abnormal in cells with abnormal expression of S100A4. They found that the levels of VEGF and MMP-9 in BCPAP thyroid cancer cells expressing PTCSC3 were significantly downregulated to inhibit invasion and metastasis. This mechanism of action may be that PTCSC3 inhibits the secretion of VEGF and MMP-9 by inhibiting S100A4 expression, thereby inhibiting the invasion and metastasis of thyroid cancer cells.

\section{MEG3}

Maternal expressed gene 3 (MEG3) located on human chromosome $14 \mathrm{q} 32$ is usually expressed in many normal tissues. However, downregulation of $M E G 3$ expression is closely related to tumorigenesis. A decrease in MEG3 expression has been found in many human tumors, including in the stomach, tongue, prostate, lung, and bladder, and it exerts its function in tumor cell proliferation, migration, and invasion (46-51). Wang et al. (52) reported that expression of MEG3 is lower in metastatic tissues of PTC than that in non-metastatic thyroid cancer tissues. In human thyroid cancer cell lines, high levels of MEG3 can inhibit invasion and metastasis of thyroid cancer cells. This study showed that the Racl gene is negatively regulated by $M E G 3$ at the posttranscriptional level in thyroid cancer. MEG3 inhibits migration and invasion of thyroid cancer cells by acting on Rac1 and is linked with lymph node metastasis. Rac1 is one of the most studied Rho GTPases. It exerts its regulatory function in cell proliferation, participates in the signaling pathway promoting cell survival, and plays a central role in the control of cell adhesion and migration. Additionally, Liu et al. (53) reported that MEG3 inhibits proliferation of 131 I-resistant TC cells by negative regulation of miR-182, induces apoptosis, and enhances DNA damage. These results indicate that MEG3 functions as a tumor suppressor, resulting in the inhibition of tumor growth in thyroid cancer.

\section{Epigenetic Modification}

lncRNAs have been reported to directly bind target proteins and conduct post-transcriptional modification in many cancers (5457). Histone modifications are a type of epigenetic modifications. A variety of lncRNAs are reportedly involved in the biological activities of thyroid cancer through histone modification.

\section{BANCR}

BRAF-activated ncRNA (BANCR), a 693 bp-long transcript on chromosome 9q21.12, was first discovered in 2012 by Flockhart et al., and is considered a potential regulator of melanoma cell metastasis (58). BANCR is strongly linked to BRAF V600E, the most prevalent mutation in thyroid cancer genes. Studies have shown that BANCR produced by the BRAF V600E mutation is also associated with the occurrence of thyroid tumors (59). $B A N C R$ has both carcinogenic and tumor suppressing effects, and can play different roles in different tumors. It has been reported that BANCR has a tumor suppressing effect in liver and bladder cancers $(60,61)$, while it acts as an oncogene in gastric, colorectal, and lung cancers (62-64).

Enhancer of zeste homolog 2 (EZH2), an oncogenic histone methyltransferase, is a well-known histone modifier. Overexpression of EZH2 has been strongly associated with several types of cancer $(65,66)$. Zheng et al. (67) found that the expression of BANCR in PTC tissues was significantly higher than that in adjacent tissues. The study showed that $B A N C R$ can be recruited by EZH2 to increase the expression level of thyroid-stimulating hormone receptor (TSHR) and promote the proliferation of IHH-4 thyroid cancer cells. TSH exerts its effects on thyroid cell proliferation by binding to its receptor, TSHR. By silencing BANCR, chromatin recruitment of EZH2 and expression of TSHR can be reduced. Zheng et al. (68) also reported that BANCR may promote the development of malignant thyroid nodules via the modulation of TSHR expression and its downstream effector, cyclin D1. However, Wang et al. found that BANCR promotes EMT in PTC cell lines by activating the Raf/MEK/ERK signaling pathway (69). Liu et al. (70) reported that $B A N C R$ affects the proliferation, invasion, and apoptosis of thyroid cancer cells through modulation of autophagy behavior. The expression of BANCR was positively related to the pathological stage of thyroid carcinoma and lymph node metastasis. In their study, Zhang et al. (71) showed that downregulation of BANCR promotes aggressiveness in PTC via the MAPK and PI3K pathways. These studies indicated that $B A N C R$ could function as both an oncogene and a tumorsuppressor gene; thus, whether BANCR is bifunctional in PTC warrants further clarifying investigation.

\section{PVT1}

lncRNA PVT1, located at chromosome 8q24.21, is highly expressed in many tumors. In a previous study, PVT1 was reported to promote the proliferation of thyroid carcinoma cells by recruiting EZH2 and mediating TSHR expression (72). Recently, Feng et al. (73) found that PVT1 is highly expressed in thyroid cancer tissues and cells, and its expression level is associated with TNM stage and lymph node metastasis in thyroid cancer. The expression level of PVT1 in patients with lymph node metastasis and tumor infiltration presented with significantly higher expression level of PVT1 than their counterparts without these aggressive disease features. IncRNA $P V T 1$, as a ceRNA of microRNA-30a, was proven to enhance the invasion and metastasis of PTC cells by mediating expression of insulin-like growth factor 1 receptor (IGF1R). IGF1R exerts its function in maintaining homeostasis as well as normal thyroid morphogenesis, and papillary thyroid hyperplasia is promoted when certain IGF1R signals are lost. MiR-30a inhibits cell invasion, migration potential, EMT, and metastatic potential by 
binding and negatively regulating expression of its target gene, lysyl oxidase $(L O X)$, which is associated with higher mortality in undifferentiated thyroid carcinoma. The association between PVT1 and thyroid cancer remains to be studied further.

\section{Signaling Pathways TGF- $\beta$ Signaling Pathway LnCRNA SPRY4-IT1}

SPRY4-IT1, a 708 bp IncRNA discovered by Khaitan et al. in 2011, is derived from an intron of the SPRY4 gene residing on chromosome $5 \mathrm{q} 31.3$. Studies have confirmed that dysregulation of SPRY4-IT1 is related to many cancers, including osteosarcoma, breast cancer, lung cancer, hepatocellular carcinoma, colorectal cancer, pancreatic cancer, and others (74-79). Zhou et al. (80) found that SPRY4-IT1 was upregulated in thyroid cancer tissues and cell lines, and its high levels were strongly correlated with lymph node metastasis, clinical stage, and poor prognosis of patients with thyroid cancer (80). Additionally, SPRY4-IT1 participates in the progress of thyroid cancer by regulating the TGF- $\beta /$ Smad signaling pathway, which may provide a new perspective for studies on thyroid cancer and SPRY4-IT1.

\section{PI3K/AKT Signaling Pathway \\ GAS5}

The gene coding for lncRNA growth arrest-specific 5 (GAS5) is $\sim 630 \mathrm{nt}$ long and is located on chromosome 1q25. GAS5 is associated with a range of malignancies, including rectal cancer, cervical cancer, glioma, and oral squamous cell carcinoma (8184). It was first reported by Abudoureyimu et al. (85) in thyroid cancer, in which GAS expression reportedly decreases. Recently, Guo et al. (86) reported that GAS5 expression was lower in thyroid cancer tissues than in benign tumor tissues. Low GAS5 expression is related to TNM staging, lymph node metastasis, multiple cancer foci, and poor prognosis in patients with thyroid cancer. Zhang et al. (87) found that GAS5 is downregulated in thyroid cancer tissues and thyroid cancer cell lines. This study showed that GAS5, as a ceRNA, acts on miR-222-3p in thyroid cancer, leading to activation of the PTEN/AKT pathway and exerting an anti-cancer effect. PTEN is a key inhibitory gene for tumor cell growth that inhibits AKT phosphorylation, and its downregulation is related to tumorigenesis. Therefore, GAS5 may be a potential prognostic marker and therapeutic target in PTC.

\section{H19}

lncRNA- H19 is located on human chromosome $11 \mathrm{p} 15.5$ and is involved in a great many cancers, including lung cancer, breast cancer, and gastric cancer, among others. One study found that $H 19$ plays a more complex role in tumorigenesis, both carcinogenic and tumor suppressive. Thus far, few studies have examined the relationship between $\mathrm{H} 19$ and thyroid cancer. Lan et al. (88) found that decreased expression of H19 in PTC is closely related to lymph node metastasis. In the future, H19 may be used to optimize management in patients with uncertain fineneedle aspiration specimens. In addition, it could be used as a potential tool to distinguish patients with and without lymph node metastasis. Liu et al. (31) and Jiao et al. (89) reported that increased H19 expression levels are associated with tumor diameter, TNM stage, lymph node metastasis, and poor prognosis in TC patients. Wang et al. (90) reported that $H 19$ can inhibit cell proliferation by downregulating IRS-1 in thyroid cancer cells. IRS1 regulates the activation of the PI3K/AKT and nuclear factor $\kappa-\beta$ signaling pathways. The PI3K/AKT pathway exerts its function in tumorigenesis. It has been shown to promote malignant transformation of tumors by enhancing cancer cell survival, proliferation, and metabolism (91). Li et al. (92) also found that $H 19$ plays an oncogenic role in thyroid cancer through the PI3K/AKT pathway. However, Liu et al. (93) found that H19 acts as an oncogene in thyroid cancer. $\mathrm{H} 19$ can promote invasion and metastasis of thyroid cancer cells in vivo and in vitro. As a ceRNA, lncRNA antagonizes the function of H19/miR-17-5p and upregulates the expression of their target YES1, inducing cell cycle progression. Knocking down H19 can inhibit cell proliferation in vivo and in vitro. YES1 belongs to the protein tyrosine kinase family and is upregulated in many cancers. In addition, the study linked $H 19$ overexpression to poor prognosis in patients with thyroid cancer (93).

\section{EMT Pathway \\ CASC2}

lncRNA cancer susceptibility candidate 2 (CASC2), located on chromosome 10q26, has been associated with a variety of malignancies. However, studies on the association between CASC2 and thyroid cancer are rare. Xiong et al. (94) reported that CASC2 is downregulated in thyroid cancer tissues, and its overexpression in vitro can inhibit the proliferation of thyroid cancer cells by interfering with the cell cycle. Downregulation of CASC2 expression was significantly associated with multifocality and TNM staging of tumors, but not with other clinical pathological parameters. CASC2 downregulation indicates poor prognosis in thyroid cancer. Recently, CASC2 has been reported to be significantly downregulated in tissue and plasma samples from patients with PTC compared to levels in patients with nodular goiter, and its expression level is significantly related to LNM (95). In addition, this study demonstrated that CASC2 affects thyroid cancer cell invasion and metastasis by regulating the EMT pathway, and may be a predictor of LNM in patients with thyroid cancer. Compared with that in normal tissues, the expression of CASC2 was significantly decreased in PTC tumors, and the downregulation of CASC2 was significantly associated with tumor size, presence of multifocal lesions, and advanced pathological stage. Overexpression of CASC2 leads to inactivation of AKT and ERK1/2, which can significantly inhibit the proliferation of thyroid cancer cells (96).

\section{MALAT1}

Metastasis-associated lung adenocarcinoma transcript 1 (MALAT1) is a lncRNA of more than $8.0 \mathrm{~kb}$ in length, and its gene is located at 11q13.1. MALAT1 is associated with many cancers (97-99). Studies have found that MALAT1 can promote the proliferation and metastasis of thyroid cancer cells $(100,101)$. In a previous study, Huang et al. (102) examined 10 cases of follicular thyroid carcinoma tissue and 10 cases of normal thyroid tissue and found that MALAT1 was upregulated in thyroid cancer tissues. MALAT1 promotes the formation of 
blood vessels in thyroid cancer by regulating the secretion of the FGF2 protein in tumor-associated macrophages (TAMs), thereby promoting biological behaviors such as proliferation and metastasis in thyroid cancer cells. Chu et al. (101) reported that the expression level of MALAT1 was significantly upregulated in medullary thyroid carcinoma compared with that in normal thyroid tissue. Furthermore, in vitro experiments have shown that inhibition of MALAT1 exerts an anti-tumor effect and inhibits cell proliferation and invasion. Zhang et al. (103) found that MALAT1 expression was upregulated in PTC TPC1 cells induced by transforming growth factor (TGF)- $\beta$ to the EMT, which provided a new perspective for lncRNA research. This study also found that MALAT1 expression levels in poorly differentiated thyroid carcinomas and anaplastic thyroid carcinomas are significantly lower than those in normal thyroid tissues, with expression in anaplastic thyroid carcinomas (ATCs) showing the lowest levels. This was the first report of MALAT1 being downregulated in any malignancy, and it indicates that MALAT1 may be a potential tool in classification of thyroid carcinoma. Recently, Liu et al. (104) found that MALAT1 expression was upregulated in PTC tissues, and the upregulated MALAT1 expression was correlated with tumor size, lymph node metastases, and disease stage. Wen et al. (105) explored the potential correlation between MALAT1 genetic variations (single nucleotide polymorphism; SNP) and the risk of PTC. They found that MALAT1 SNP rs619586 could directly reduce $M A L A T 1$ expression, becoming a potential protective factor that reduces the risk of PTC. MALAT1 may play different roles in different thyroid tumors, and its effect is determined by the type of thyroid cancer. Gene polymorphisms may be a potential focal point in study of the relationship between lncRNA and PTC.

\section{Wnt/ $\beta$-catenin Signaling Pathway}

Certain lncRNAs function in a variety of ways. PTCSC3 can act directly on its target gene S100A4 or through a signaling pathway. Xia et al. (106) found that PTCSC3 reduces the proliferation and invasion of glioma cells by inhibiting the action of the Wnt/ $\beta$-catenin signaling pathway. Additionally, Wang et al. (107) reported that PTCSC3/miR574-5p promotes proliferation and migration of papillary thyroid carcinoma cells via the $\mathrm{Wnt} / \beta$ catenin signaling pathway.

The lncRNAs discussed above and listed in Table $\mathbf{1}$ are likely to function in thyroid cancer.

\section{THE PROMISING FUTURE OF LNCRNAS IN CANCER DIAGNOSIS AND PROGNOSIS}

Many studies have found that certain lncRNAs are stably present in human serum/plasma $(108,109)$, which may be helpful in the study of the role of serum/plasma lncRNAs in diagnosis and prognosis. Circulating markers have been widely used for disease prediction. Shi et al. (109) reported that the expression of lncRNAs in body fluids and serum/plasma have significant value in the diagnosis of many cancers. Zhou et al. (110) reported that the expression of H19 in plasma has high specificity and sensitivity for diagnosis of gastric cancer and was more effective than conventional biomarkers, such as carcinoembryonic antigen (CEA) and carbohydrate antigen 199 (CA199). Tang et al. (111) found that expression of lncRNAs in saliva is associated with the prognosis of oral squamous cell carcinoma and can provide clinics with a noninvasive and convenient screening tool. To date, many circulating lncRNAs have been shown to have diagnostic significance in thyroid cancer, including HOTAIR, H19, MALAT1, GAS5, GAS8-AS1, DLG1-AS1, ENST00000462717, ENST00000415582, TCONS_00024700, and NR_028494 (34, 80, 102, 112). The latter four are considered linked to prognosis of patients with PTC and lung metastases (113). Zhang et al. (35) identified plasma GAS8-AS1 overexpression in the serum of patients with thyroid cancer. He et al. (112) found that plasma DLG1-AS1 was upregulated in patients with PTC but not in patients with benign thyroid nodules or healthy controls. Plasma testing for biomarkers not only enables early diagnosis, avoiding poor prognoses, but also prevents unnecessary treatments. Circulating lncRNAs may be potential tumor markers for PTC diagnosis.

Thus far, many lncRNAs have been associated with PTC. Most patients with PTC have a favorable prognosis with the current therapeutic regimen, which includes surgical resection, thyroid hormone suppression, and radioactive iodine therapy. However, a small proportion of PTC cases have poor prognoses due to metastases. Therefore, it is critical to differentiate these patients from lower risk cases at the early stage. Screening for some lncRNAs could contribute to molecular stratification of aggressive and indolent PTC and accumulating evidence has implicated lncRNAs in PTC LNM. Studies carried out via microarray, TCGA PTC cohorts, or ceRNA networks have found that many previously uncharacterized lncRNAs are associated with poor prognosis or LNM. Song et al. (114) found that high ENS-653 expression is associated with more advanced tumor stage and poorer disease-free survival. RP11-547D24.1 and UNC5B-AS1 could differentiate patients with different stages of PTC, and some lncRNAs play vital roles in determining histological cancer type (115). Additionally, some lncRNAs are associated with LNM (116).

Although the expression of lncRNAs in serum is meaningful for studying certain biological behaviors of thyroid cancer, the measurement of IncRNAs in serum is affected by many factors. Studies have found that lncRNAs contained in blood cells may affect the measurement of lncRNAs in serum (117). The release of lncRNAs from blood cells during coagulation can cause the concentration of lncRNAs in serum to be higher than that in plasma. Factors such as diet and environment of the subjects also affect serum lncRNA concentrations. Food is a key confounding factor, and it is difficult for lncRNAs from food to be distinguished from endogenous lncRNAs once the former enter the circulation $(118,119)$. There are other factors that may affect circulating lncRNAs. The use of lncRNAs as molecular markers for clinical diagnosis may present significant challenges.

Thus far, several molecular markers, including RAS, RET$P T C$, and BRAF (V600E) gene mutations, have been linked to 
TABLE 1 | LncRNAs are related to thyroid cancer.

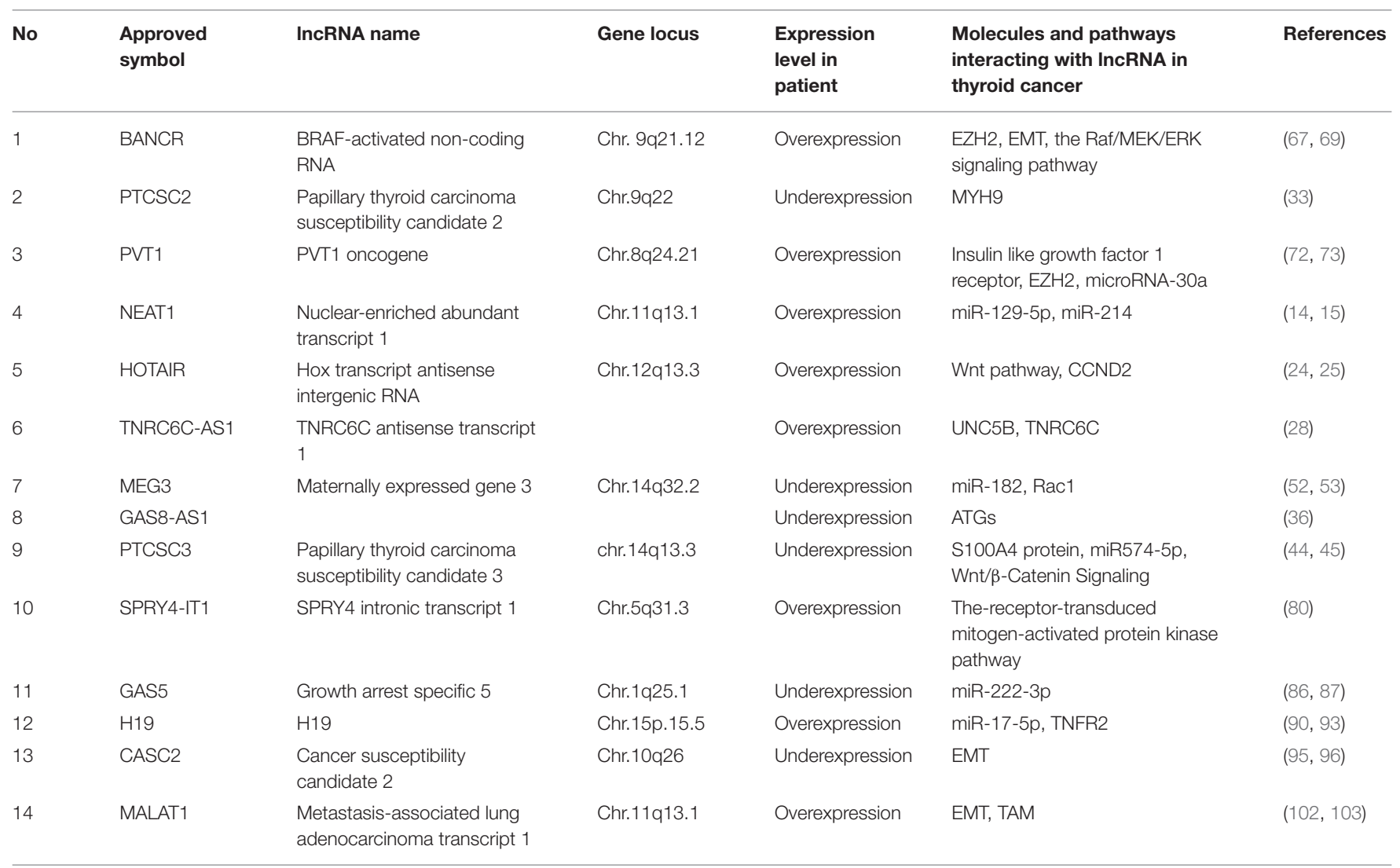

PTC. BRAF mutations are the most common. According to the exome and RNA sequences, proteomic profiles, and epigenetic changes, Agrawal et al. (120) subdivided PTCs into BRAF-like and RAS-like groups. The RET (+) PTCs were much closer to BRAF-like PTCs than to RAS-like ones. A study reported that RAS mutations are more frequent in poorly differentiated thyroid carcinomas and anaplastic ones, but are rare in PTCs (121). BRAF (V600E) is a thyroid cancer-specific gene, and many studies have showed a significant association between the BRAFV600E mutation in PTC and factors characteristic of poor prognosis. Studies found that there are relationships between lncRNAs in PTC and the most common genetic alterations in PTC. Heejei Yoon et al. (122) reported that NAMA underexpression correlates with BRAF mutation. Wang et al. (123) reported that BRAF mutation is associated with the overexpression of many oncogenic molecules in PTC, including CCND1, CDKN1A, PERP, THBS1, and ZMAT3. Further, patients with BRAFV600E mutation had a higher expression of ENS653 (114). COMET, a new natural antisense lncRNA, maps on chromosome 7q31.2 and is highly expressed in BRAF-like carcinomas (124). COMET is a MET regulator and has been identified as a new MAPK-induced cytosolic lncRNA. Rusinek et al. (125) identified 18 BRAF-induced genes that are specific for BRAF V600E-driven PTC and seven BRAF-induced genes had not been previously reported as being related to BRAF mutation or thyroid carcinoma: MMD, ITPR3, AACS, LAD1, PVRL3,
$A L D H 3 B 1$, and RASA1. These results reported the influence of the BRAFV600E mutation on early PTC gene expression profile. Additionally, the expression of some lncRNAs are associated with BRAF (V600E) mutation. These lncRNAs may be associated with poor prognosis in PTC; thus, IncRNAs with subtype-specific expression stratified by BRAF mutation might be significant in individual molecular subtypes.

Related treatments targeting lncRNAs are under development, including nucleic acid-based therapies and plasmid-based therapies. At least 25 RNAi-based drug candidates are under clinical evaluation (126). Moreover, plasmid-based therapies are also being used in clinical phase III trials of bladder cancer (127). The idea that lncRNAs may be therapeutic targets in thyroid cancer has been proposed, and targeted therapies may be under development (31).

\section{CONCLUSION AND PERSPECTIVE}

As molecular markers for tumor diagnosis and treatment, lncRNAs have been shown to participate in the proliferation, invasion, and metastasis of various malignant cells. In thyroid cancer, lncRNAs are potential biomarkers that could be used in diagnosis and in predicting invasion and metastasis. It has been reported that lncRNAs can be detected in plasma, serum, and other liquids with good stability and easy detection, suggesting new avenues for research. However, the regulatory mechanisms 
of lncRNAs in thyroid cancer remain to be further explored. There are still many difficulties in the extraction of lncRNA and future clinical applications. For example, under existing storage conditions, it is difficult to protect samples from RNA degradation, and the lncRNA database is relatively imperfect.

lncRNA is expected to become a target in gene-targeted therapy. Cancer treatment can be achieved by silencing or knocking down certain oncogenes. With the development of precision medicine, genetic diagnosis and treatment will become the trend, but there are still great challenges in research into lncRNA.

\section{REFERENCES}

1. Ferlay J, Soerjomataram I, Dikshit R, Eser S, Mathers C, Rebelo M, et al. Cancer incidence and mortality worldwide: sources, methods and major patterns in GLOBOCAN 2012. Int J Cancer. (2015) 136:E359-86. doi: $10.1002 /$ ijc. 29210

2. Davies L, Welch HG. Current thyroid cancer trends in the United States. JAMA Otolaryngol Head Neck Surg. (2014) 140:317-22. doi: 10.1001/jamaoto.2014.1

3. Haugen BR, Alexander EK, Bible KC, Doherty GM, Mandel SJ, Nikiforov YE, et al. 2015 American thyroid association management guidelines for adult patients with thyroid nodules and differentiated thyroid cancer: the American Thyroid Association guidelines task force on thyroid nodules and differentiated thyroid cancer. Thyroid. (2016) 26:1-133. doi: $10.1089 /$ thy. 2015.0020

4. Yang M, Tian J, Guo X, Yang Y, Guan R, Qiu M, et al. Long noncoding RNA are aberrantly expressed in human papillary thyroid carcinoma. Oncol Lett. (2016) 12:544-52. doi: 10.3892/ol.2016.4653

5. Li QY, Li HH, Zhang L, Zhang CM, Yan WT, Wang C. Identification of novel long non-coding RNA biomarkers for prognosis prediction of papillary thyroid cancer. Oncotarget. (2017) 8:46136-44. doi: 10.18632/oncotarget.17556

6. Hutchinson JN, Ensminger AW, Clemson CM, Lynch CR, Lawrence JB, Chess A. A screen for nuclear transcripts identifies two linked noncoding RNAs associated with SC35 splicing domains. BMC Genomics. (2007) 8:39. doi: 10.1186/1471-2164-8-39

7. Sun C, Li S, Zhang F, Xi YY, Wang L, Bi Y, et al. Long non-coding RNA NEAT1 promotes non-small cell lung cancer progression through regulation of miR-377-3p-E2F3 pathway. Oncotarget. (2016) 7:51784-814. doi: 10.18632/oncotarget.10108

8. Zhou K, Zhang C, Yao H, Zhang X, Zhou Y, Che Y, et al. Knockdown of long non-coding RNA NEAT1 inhibits glioma cell migration and invasion via modulation of SOX2 targeted by miR-132. Mol Cancer. (2018) 17:105. doi: 10.1186/s12943-018-0849-2

9. Li X, Wang S, Li Z, Long X, Guo Z, Zhang G, et al. Retracted: NEAT1 induces epithelial-mesenchymal transition and 5-FU resistance through the miR-129/ZEB2 axis in breast cancer. FEBS Lett. (2016) 591:570. doi: 10.1002/1873-3468.12474

10. Wang $\mathrm{P}, \mathrm{Wu} \mathrm{T}$, Zhou $\mathrm{H}$, Jin Q, He G, Yu H, et al. Long noncoding RNA NEAT1 promotes laryngeal squamous cell cancer through regulating miR-107/CDK6 pathway. J Exp Clin Cancer Res. (2016) 35:22. doi: 10.1186/s13046-016-0297-z

11. Cao J, Zhang Y, Yang J, He S, Li M, Yan S, et al. NEAT1 regulates pancreatic cancer cell growth, invasion and migration though mircroRNA-335-5p_cmet axis. Am J Cancer Res. (2016) 6:2361-74.

12. Gong W, Zheng J, Liu X, Ma J, Liu Y, Xue Y. Knockdown of NEAT1 restrained the malignant progression of glioma stem cells by activating microRNA let-7e. Oncotarget. (2016) 7:62208-23. doi: 10.18632/oncotarget.11403

13. Lei $\mathrm{H}, \mathrm{Gao} \mathrm{Y}, \mathrm{Xu} \mathrm{X}$. LncRNA TUG1 influences papillary thyroid cancer cell proliferation, migration and EMT formation through targeting miR-145. Acta Biochim Biophys Sin. (2017) 49:588-97. doi: 10.1093/abbs/gmx047

\section{AUTHOR CONTRIBUTIONS}

XP provided direction. XP, JX, and LM wrote the manuscript. WC and KZ made significant revisions to the manuscript. All authors read and approved the final manuscript.

\section{FUNDING}

The present review was supported by grants from the Jilin Province Science and Technology Fund (20160101043JC) and the Social Development Project of Jilin province (20190303165SF).

14. Li JH, Zhang SQ, Qiu XG, Zhang SJ, Zheng SH, Zhang DH. Long non-coding RNA NEAT1 promotes malignant progression of thyroid carcinoma by regulating miRNA-214. Int J Oncol. (2017) 50:708-16. doi: 10.3892/ijo.2016.3803

15. Zhang H, Cai Y, Zheng L, Zhang Z, Lin X, Jiang N. Long noncoding RNA NEAT1 regulate papillary thyroid cancer progression by modulating miR-129-5p/KLK7 expression. J Cell Physiol. (2018) 233:6638-48. doi: $10.1002 /$ jcp. 26425

16. Sun W, Lan X, Zhang H, Wang Z, Dong W, He L, et al. NEAT ${ }_{1 \_2}$ functions as a competing endogenous RNA to regulate ATAD2 expression by sponging microRNA-106b-5p in papillary thyroid cancer. Cell Death Dis. (2018) 9:380. doi: 10.1038/s41419-018-0418-z

17. Wu G, Liu H, He H, Wang Y, Lu X, Yu Y, et al. miR-372 down-regulates the oncogene ATAD2 to influence hepatocellular carcinoma proliferation and metastasis. BMC Cancer. (2014) 14:107. doi: 10.1186/1471-2407-14-107

18. Liu C, Feng Z, Chen T, Lv J, Liu P, Jia L, et al. Downregulation of NEAT1 reverses the radioactive iodine resistance of papillary thyroid carcinoma cell via miR-101-3p/FN1/PI3K-AKT signaling pathway. Cell Cycle. (2019) 18:167-203. doi: 10.1080/15384101.2018.1560203

19. Xia S, Wang C, Postma EL, Yang Y, Ni X, Zhan W. Fibronectin 1 promotes migration and invasion of papillary thyroid cancer and predicts papillary thyroid cancer lymph node metastasis. Oncotargets Ther. (2017) 10:1743-55. doi: 10.2147/OTT.S122009

20. Berrondo C, Flax J, Kucherov V, Siebert A, Osinski T, Rosenberg A, et al. Expression of the long non-coding RNA HOTAIR correlates with disease progression in bladder cancer and is contained in bladder cancer patient urinary exosomes. PLoS ONE. (2016) 11:e0147236. doi: 10.1371/journal.pone.0147236

21. Liu L, Cui S, Wan T, Li X, Tian W, Zhang R, et al. Long non-coding RNA HOTAIR acts as a competing endogenous RNA to promote glioma progression by sponging miR-126-5p. J Cell Physiol. (2018) 233:6822-31. doi: $10.1002 /$ jcp.26432

22. Yang $\mathrm{T}, \mathrm{He} \mathrm{X}$, Chen $\mathrm{A}$, Tan $\mathrm{K}, \mathrm{Du} \mathrm{X}$. LncRNA HOTAIR contributes to the malignancy of hepatocellular carcinoma by enhancing epithelialmesenchymal transition via sponging miR-23b-3p from ZEB1. Gene. (2018) 670:114-22. doi: 10.1016/j.gene.2018.05.061

23. Zhang Y, Yu S, Jiang L, Wang X, Song X. HOTAIR is a promising novel biomarker in patients with thyroid cancer. Exp Ther Med. (2017) 13:2274-8. doi: 10.3892/etm.2017.4231

24. Di W, Li Q, Shen W, Guo H, Zhao S. The long non-coding RNA HOTAIR promotes thyroid cancer cell growth, invasion and migration through the miR-1-CCND2 axis. Am J Cancer Res. (2017) 7:1298-309.

25. Zhu H, Lv Z, An C, Shi M, Pan W, Zhou L, et al. Onco-lncRNA HOTAIR and its functional genetic variants in papillary thyroid carcinoma. Sci Rep. (2016) 6:31969. doi: 10.1038/srep31969

26. Chen S, Fan X, Gu H, Zhang L, Zhao W. Competing endogenous RNA regulatory network in papillary thyroid carcinoma. Mol Med Rep. (2018) 18:695-704. doi: 10.3892/mmr.2018.9009

27. Ling H, Yang H, Weng D, Luo Y, Liang C, Pan D, et al. Overexpression of LncRNA HOTAIR is associated with poor prognosis in thyroid carcinoma: a study based on TCGA and GEO data. Horm Metab Res. (2017) 49:388-99. doi: 10.1055/s-0043-103346 
28. Hou S, Lin Q, Guan F, Lin C. LncRNA TNRC6C-AS1 regulates UNC5B in thyroid cancer to influence cell proliferation, migration, and invasion as a competing endogenous RNA of miR-129-5p. J Cell Biochem. (2018) 119:8304-16. doi: 10.1002/jcb.26868

29. Kong C, Zhan B, Piao C, Zhang Z, Zhu Y, Li Q. Overexpression of UNC5B in bladder cancer cells inhibits proliferation and reduces the volume of transplantation tumors in nude mice. BMC Cancer. (2016) 16:892. doi: 10.1186/s12885-016-2922-9

30. Muhanhali D, Zhai T, Jiang J, Ai Z, Zhu W, Ling Y. Long non-coding antisense RNA TNRC6C-AS1 is activated in papillary thyroid cancer and promotes cancer progression by suppressing TNRC6C expression. Front Endocrinol. (2018) 9:360. doi: 10.3389/fendo.2018.00360

31. Liu N, Zhou Q, Qia YH, Wang H, Yang L, Fan QY. Effects of long non-coding RNA H19 and microRNA let7a expression on thyroid cancer prognosis. Exp Mol Pathol. (2017) 103:71-7. doi: 10.1016/j.yexmp.2017.06.004

32. He H, Li W, Liyanarachchi S, Srinivas M, Wang Y, Akagi K, et al. Multiple functional variants in long-range enhancer elements contribute to the risk of SNP rs965513 in thyroid cancer. Proc Natl Acad Sci USA. (2015) 112:612833. doi: 10.1073/pnas.1506255112

33. Wang Y, He H, Li W, Phay J, Shen R, Yue L, et al. MYH9 binds to lncRNA gene PTCSC2 and regulates FOXE1 in the 9q22 thyroid cancer risk locus. Proc Natl Acad Sci USA. (2017) 114:474-9. doi: 10.1073/pnas.1619917114

34. Pan W, Zhou L, Ge M, Zhang B, Yang X, Xiong X, et al. Whole exome sequencing identifies IncRNA GAS8-AS1 and LPAR4 as novel papillary thyroid carcinoma driver alternations. Hum Mol Genet. (2016) 25:1875-84. doi: 10.1093/hmg/ddw056

35. Zhang D, Liu X, Wei B, Qiao G, Jiang T, Chen Z. Plasma lncRNA GAS8-AS1 as a potential biomarker of papillary thyroid carcinoma in Chinese patients. Int J Endocrinol. (2017) 2017:2645904. doi: 10.1155/2017/2645904

36. Qin Y, Sun W, Zhang H, Zhang P, Wang Z, Dong W, et al. LncRNA GAS8-AS1 inhibits cell proliferation through ATG5-mediated autophagy in papillary thyroid cancer. Endocrine. (2018) 59:555-64. doi: 10.1007/s12020-017-1520-1

37. Jendrzejewski J, He H, Radomska H, Li W, Tomsic J, Liyanarachchi S, et al. The polymorphism rs 944289 predisposes to papillary thyroid carcinoma through a large intergenic noncoding RNA gene of tumor suppressor type. Proc Natl Acad Sci USA. (2012) 109:8646-51. doi: 10.1073/pnas.1205654109

38. Rogounovitch TI, Bychkov A, Takahashi M, Mitsutake N, Nakashima M, Nikitski AV, et al. The common genetic variant rs944289 on chromosome 14q13.3 associates with risk of both malignant and benign thyroid tumors in the Japanese population. Thyroid. (2015) 25:333-40. doi: 10.1089/thy.2014.0431

39. Hou S, Tian T, Qi D, Sun K, Yuan Q, Wang Z, et al. S100A4 promotes lung tumor development through beta-catenin pathway-mediated autophagy inhibition. Cell Death Dis. (2018) 9:277. doi: 10.1038/s41419-018-0319-1

40. Zuo Z, Zhang P, Lin F, Shang W, Bi R, Lu F, et al. Interplay between Trx-1 and S100P promotes colorectal cancer cell epithelial-mesenchymal transition by up-regulating S100A4 through AKT activation. J Cell Mol Med. (2018) 22:2430-41. doi: 10.1111/jcmm.13541

41. Yu A, Wang Y, Bian Y, Chen L, Guo J, Shen W, et al. IL-1beta promotes the nuclear translocaiton of S100A4 protein in gastric cancer cells MGC803 and the cell's stem-like properties through PI3K pathway. J Cell Biochem. (2018) 119:8163-73. doi: 10.1002/jcb.26813

42. Ruma IMW, Kinoshita R, Tomonobu N, Inoue Y, Kondo E, Yamauchi A, et al. Embigin promotes prostate cancer progression by S100A4dependent and-independent mechanisms. Cancers. (2018) 10:239. doi: 10.3390/cancers10070239

43. Liu Y, Geng YH, Yang H, Yang H, Zhou YT, Zhang HQ, et al. Extracellular ATP drives breast cancer cell migration and metastasis via S100A4 production by cancer cells and fibroblasts. Cancer Lett. (2018) 430:1-10. doi: 10.1016/j.canlet.2018.04.043

44. Jendrzejewski J, Thomas A, Liyanarachchi S, Eiterman A, Tomsic J, He $\mathrm{H}$, et al. PTCSC3 is involved in papillary thyroid carcinoma development by modulating S100A4 gene expression. J Clin Endocrinol Metab. (2015) 100:E1370-7. doi: 10.1210/jc.2015-2247

45. Donato R, Cannon BR, Sorci G, Riuzzi F, Hsu K, Weber DJ, et al. Functions of S100 Proteins. Cur Mol Med. (2013) 13:24-57. doi: $10.2174 / 156652413804486214$
46. Ribarska T, Goering W, Droop J, Bastian KM, Ingenwerth M, Schulz WA Deregulation of an imprinted gene network in prostate cancer. Epigenetics. (2014) 9:704-17. doi: 10.4161/epi.28006

47. Yan J, Guo X, Xia J, Shan T, Gu C, Liang Z, et al. MiR-148a regulates MEG3 in gastric cancer by targeting DNA methyltransferase 1. Med Oncol. (2014) 31:879. doi: 10.1007/s12032-014-0879-6

48. Lu K, Li W, Liu X, Sun M, Zhang M, Wu W, et al. Long non-coding RNA MEG3 inhibits NSCLC cells proliferation and induces apoptosis by affecting p53 expression. BMC Cancer. (2013) 13:461. doi: 10.1186/1471-2407-13-461

49. Jia LF, Wei SB, Gan YH, Guo Y, Gong K, Mitchelson K, et al. Expression, regulation and roles of miR-26a and MEG3 in tongue squamous cell carcinoma. Int J Cancer. (2014) 135:2282-93. doi: 10.1002/ijc.28667

50. Ying L, Huang Y, Chen H, Wang Y, Xia L, Chen Y, et al. Downregulated MEG3 activates autophagy and increases cell proliferation in bladder cancer. Mol Biosyst. (2013) 9:407-11. doi: 10.1039/c2mb25386k

51. Wang P, Ren Z, Sun P. Overexpression of the long non-coding RNA MEG3 impairs in vitro glioma cell proliferation. J Cell Biochem. (2012) 113:1868-74. doi: $10.1002 /$ jcb. 24055

52. Wang C, Yan G, Zhang Y, Jia X, Bu P. Long non-coding RNA MEG3 suppresses migration and invasion of thyroid carcinoma by targeting of Rac1. Neoplasma. (2015) 62:541-9. doi: 10.4149/neo_2015_065

53. Liu Y, Yue P, Zhou T, Zhang F, Wang H, Chen X. LncRNA MEG3 enhances (131)I sensitivity in thyroid carcinoma via sponging miR-182. Biomed Pharmacother. (2018) 105:1232-9. doi: 10.1016/j.biopha.2018.06.087

54. Xiong Y, Kuang W, Lu S, Guo H, Wu M, Ye M, et al. Long noncoding RNA HOXB13-AS1 regulates HOXB13 gene methylation by interacting with EZH2 in glioma. Cancer Med. (2018) 7:4718-28. doi: 10.1002/cam4.1718

55. Gu W, Zhang E, Song L, Tu L, Wang Z, Tian F, et al. Long noncoding RNA HOXD-AS1 aggravates osteosarcoma carcinogenesis through epigenetically inhibiting p57 via EZH2. Biomed Pharmacother. (2018) 106:890-5. doi: $10.1016 /$ j.biopha.2018.06.173

56. Shang Y. LncRNA THOR acts as a retinoblastoma promoter through enhancing the combination of c-myc mRNA and IGF2BP1 protein. Biomed Pharmacother. (2018) 106:1243-9. doi: 10.1016/j.biopha.2018.07.052

57. Chen S, Wang LL, Sun KX, Liu Y, Guan X, Zong ZH, et al. LncRNA TDRG1 enhances tumorigenicity in endometrial carcinoma by binding and targeting VEGF-A protein. Biochim Biophys Acta. (2018) 1864:3013-21. doi: 10.1016/j.bbadis.2018.06.013

58. Flockhart RJ, Webster DE, Qu K, Mascarenhas N, Kovalski J, Kretz M, et al. BRAFV600E remodels the melanocyte transcriptome and induces BANCR to regulate melanoma cell migration. Genome Res. (2012) 22:100614. doi: 10.1101/gr.140061.112

59. Liao T, Qu N, Shi R, Guo K, Ma B, Cao Y, et al. BRAF-activated LncRNA functions as a tumor suppressor in papillary thyroid cancer. Oncotarget. (2017) 8:238-47. doi: 10.18632/oncotarget.10825

60. Taheri M, Omrani MD, Ghafouri-Fard S. Long non-coding RNA expression in bladder cancer. Biophys Rev. (2018) 10:1205-13. doi: 10.1007/s12551-017-0379-y

61. Li J, Wang J, Zhou W, Zhang S, Le Y, He R. Downregulation of BRAFactivated non-coding RNA suppresses the proliferation, migration and invasion, and induces apoptosis of hepatocellular carcinoma cells. Oncol Lett. (2017) 14:4751-7. doi: 10.3892/ol.2017.6770

62. Ma S, Yang D, Liu Y, Wang Y, Lin T, Li Y, et al. LncRNA BANCR promotes tumorigenesis and enhances adriamycin resistance in colorectal cancer. Aging. (2018) 10:2062-78. doi: 10.18632/aging.101530

63. Zhu ZJ, He JK. TINCR facilitates non-small cell lung cancer progression through BRAF-activated MAPK pathway. Biochem Biophys Res Commun. (2018) 497:971-7. doi: 10.1016/j.bbrc.2018.02.059

64. Li L, Zhang L, Zhang Y, Zhou F. Increased expression of LncRNA BANCR is associated with clinical progression and poor prognosis in gastric cancer. Biomed Pharmacother. (2015) 72:109-12. doi: 10.1016/j.biopha.2015. 04.007

65. Borbone E, Troncone G, Ferraro A, Jasencakova Z, Stojic L, Esposito F, et al. Enhancer of zeste homolog 2 overexpression has a role in the development of anaplastic thyroid carcinomas. J Clin Endocrinol Metab. (2011) 96:1029-38. doi: $10.1210 /$ jc. $2010-1784$

66. Esposito F, Tornincasa M, Pallante P, Federico A, Borbone E, Pierantoni GM, et al. Down-regulation of the miR-25 and miR-30d contributes to the 
development of anaplastic thyroid carcinoma targeting the polycomb protein EZH2. J Clin Endocrinol Metab. (2012) 97:E710-8. doi: 10.1210/jc.2011-3068

67. Zheng $\mathrm{H}$, Wang $\mathrm{M}$, Jiang $\mathrm{L}$, Chu $\mathrm{H}, \mathrm{Hu}$ J, Ning J, et al. BRAF-activated long noncoding RNA modulates papillary thyroid carcinoma cell proliferation through regulating thyroid stimulating hormone receptor. Cancer Res Treat. (2016) 48:698-707. doi: 10.4143/crt.2015.118

68. Zheng H, Xu J, Hao S, Liu X, Ning J, Song X, et al. Expression of BANCR promotes papillary thyroid cancer by targeting thyroid stimulating hormone receptor. Oncol Lett. (2018) 16:2009-15. doi: 10.3892/ol.2018.8810

69. Wang Y, Gu J, Lin X, Yan W, Yang W, Wu G. IncRNA BANCR promotes EMT in PTC via the Raf/MEK/ERK signaling pathway. Oncol Lett. (2018) 15:5865-70. doi: 10.3892/ol.2018.8017

70. Liu T, Zhao Y, Wang L, Jia H, Cui D, Si Y, et al. [Effects of serine/threonineprotein kinase B-Raf-activated long-chain non-coding RNA on apoptosis and autophagy in thyroid carcinoma cells]. Zhong Nan Da Xue Xue Bao Yi Xue Ban. (2018) 43:747-53. doi: 10.11817/j.issn.1672-7347.2018.07.008

71. Zhang J, Du Y, Zhang X, Li M, Li X. Downregulation of BANCR promotes aggressiveness in papillary thyroid cancer via the MAPK and PI3K pathways. J Cancer. (2018) 9:1318-28. doi: 10.7150/jca.20150

72. Zhou Q, Chen J, Feng J, Wang J. Long noncoding RNA PVT1 modulates thyroid cancer cell proliferation by recruiting EZH2 and regulating thyroidstimulating hormone receptor (TSHR). Tumor Biol. (2016) 37:3105-13. doi: 10.1007/s13277-015-4149-9

73. Feng K, Liu Y, Xu LJ, Zhao LF, Jia CW, Xu MY. Long noncoding RNA PVT1 enhances the viability and invasion of papillary thyroid carcinoma cells by functioning as ceRNA of microRNA-30a through mediating expression of insulin like growth factor 1 receptor. Biomed Pharmacother. (2018) 104:68698. doi: 10.1016/j.biopha.2018.05.078

74. Li Z, Shen J, Chan MTV, Wu WKK. The long non-coding RNA SPRY4-IT1: an emerging player in tumorigenesis and osteosarcoma. Cell Prolif. (2018) 51:e12446. doi: 10.1111/cpr.12446

75. Shi Y, Li J, Liu Y, Ding J, Fan Y, Tian Y, et al. The long noncoding RNA SPRY4-IT1 increases the proliferation of human breast cancer cells by upregulating ZNF703 expression. Mol Cancer. (2015) 14:51. doi: 10.1186/s12943-015-0318-0

76. Guo W, Zhong K, Wei H, Nie C, Yuan Z. Long non-coding RNA SPRY4-IT1 promotes cell proliferation and invasion by regulation of Cdc20 in pancreatic cancer cells. PLoS ONE. (2018) 13:e0193483. doi: 10.1371 /journal.pone. 0193483

77. Wen X, Han XR, Wang YJ, Fan SH, Zhuang J, Zhang ZF, et al. Effects of long noncoding RNA SPRY4-IT1-mediated EZH2 on the invasion and migration of lung adenocarcinoma. J Cell Biochem. (2018) 119:1827-40. doi: $10.1002 /$ jcb. 26344

78. Yu G, Lin J, Liu C, Hou K, Liang M, Shi B. Long non-coding RNA SPRY4IT1 promotes development of hepatic cellular carcinoma by interacting with ERRalpha and predicts poor prognosis. Sci Rep. (2017) 7:17176. doi: 10.1038/s41598-017-16781-9

79. Jin J, Chu Z, Ma P, Meng Y, Yang Y. Long non-coding RNA SPRY4-IT1 promotes proliferation and invasion by acting as a ceRNA of miR-101$3 p$ in colorectal cancer cells. Tumour Biol. (2017) 39:1010428317716250. doi: $10.1177 / 1010428317716250$

80. Zhou H, Sun Z, Li S, Wang X, Zhou X. LncRNA SPRY4-IT was concerned with the poor prognosis and contributed to the progression of thyroid cancer. Cancer Gene Ther. (2018) 25:39-46. doi: 10.1038/s41417-017-0003-0

81. Song J, Shu H, Zhang L, Xiong J. Long noncoding RNA GAS5 inhibits angiogenesis and metastasis of colorectal cancer through the Wnt/beta-catenin signaling pathway. J Cell Biochem. (2019) 120:6937-51. doi: $10.1002 /$ jcb. 27743

82. Zeng B, Li Y, Jiang F, Wei C, Chen G, Zhang W, et al. LncRNA GAS5 suppresses proliferation, migration, invasion, and epithelial-mesenchymal transition in oral squamous cell carcinoma by regulating the miR-21/PTEN axis. Exp Cell Res. (2019) 374:365-73. doi: 10.1016/j.yexcr.2018.12.014

83. Liu Q, Yu W, Zhu S, Cheng K, Xu H, Lv Y, et al. Long noncoding RNA GAS5 regulates the proliferation, migration, and invasion of glioma cells by negatively regulating miR-18a-5p. J Cell Physiol. (2018) 234:757-68. doi: $10.1002 /$ jcp. 26889

84. Gao J, Liu L, Li G, Cai M, Tan C, Han X, et al. LncRNA GAS5 confers the radio sensitivity of cervical cancer cells via regulating
miR-106b/IER3 axis. Int J Biol Macromol. (2018) 126:994-1001. doi: 10.1016/j.ijbiomac.2018.12.176

85. Abudoureyimu A, Maimaiti R, Magaoweiya S, Bagedati D, Wen H. Identification of long non-coding RNA expression profile in tissue and serum of papillary thyroid carcinoma. IJCEP. (2016) 9:1177-85.

86. Guo LJ, Zhang S, Gao B, Jiang Y, Zhang XH, Tian WG, et al. Low expression of long non-coding RNA GAS5 is associated with poor prognosis of patients with thyroid cancer. Exp Mol Pathol. (2017) 102:500-4. doi: 10.1016/j.yexmp.2017.05.008

87. Zhang X, Ye Y, Zhao S. LncRNA Gas5 acts as a ceRNA to regulate PTEN expression by sponging miR-222-3p in papillary thyroid carcinoma. Oncotarget. (2018) 9:3519-30. doi: 10.18632/oncotarget.23336

88. Lan X, Sun W, Dong W, Wang Z, Zhang T, He L, et al. Downregulation of long noncoding RNA H19 contributes to the proliferation and migration of papillary thyroid carcinoma. Gene. (2018) 646:98-105. doi: 10.1016/j.gene.2017.12.051

89. Jiao X, Lu J, Huang Y, Zhang J, Zhang H, Zhang K. Long non-coding RNA H19 may be a marker for prediction of prognosis in the follow-up of patients with papillary thyroid cancer. Cancer Biomark. (2019) 26:203-7. doi: 10.3233/CBM-190273

90. Wang P, Liu G, Xu W, Liu H, Bu Q, Sun D. Long noncoding RNA H19 inhibits cell viability, migration, and invasion via downregulation of IRS1 in thyroid cancer cells. Technol Cancer Res Treat. (2017) 16:1102-12. doi: $10.1177 / 1533034617733904$

91. Chen CJ, Dong H, Liu S, Yu L, Yan DX, Yao XW, et al. Long noncoding RNA MHENCR promotes melanoma progression via regulating miR-425_489mediated PI3K-Akt pathway. Am J Transl Res. (2017) 9:90-102.

92. Li X, Li Q, Jin X, Guo H, Li Y. Long non-coding RNA H19 knockdown inhibits the cell viability and promotes apoptosis of thyroid cancer cells through regulating the PI3K/AKT pathway. Exp Ther Med. (2019) 18:18639. doi: $10.3892 /$ etm. 2019.7720

93. Liu L, Yang J, Zhu X, Li D, Lv Z, Zhang X. Long noncoding RNA H19 competitively binds miR-17-5p to regulate YES1 expression in thyroid cancer. FEBS J. (2016) 283:2326-39. doi: 10.1111/febs.13741

94. Xiong $\mathrm{X}, \mathrm{Zhu} \mathrm{H}$, Chen $\mathrm{X}$. Low expression of long noncoding RNA CASC2 indicates a poor prognosis and promotes tumorigenesis in thyroid carcinoma. Biomed Pharmacother Biomed Pharmacother. (2017) 93:391-7. doi: 10.1016/j.biopha.2017.06.063

95. Zhou T, Zhong M, Zhang S, Wang Z, Xie R, Xiong C, et al. LncRNA CASC2 expression is down- regulated in papillary thyroid cancer and promotes cell invasion by affecting EMT pathway. Cancer Biomark. (2018) 23:185-91. doi: $10.3233 / \mathrm{CBM}-181198$

96. Huang F, Zhang Q, Chen W, Zhang H, Lu G, Chen J, et al. Long noncoding RNA cancer susceptibility candidate 2 suppresses papillary thyroid carcinoma growth by inactivating the AKT/ERK1/2 signaling pathway. J Cell Biochem. (2019) 120:10380-90. doi: 10.1002/ jcb. 28322

97. Wu C, Zhu X, Tao K, Liu W, Ruan T, Wan W, et al. MALAT1 promotes the colorectal cancer malignancy by increasing DCP1A expression and miR203 downregulation. Mol Carcinog. (2018) 57:1421-31. doi: 10.1002/mc.22868

98. Wang Z, Katsaros D, Biglia N, Shen Y, Fu Y, Loo LWM, et al. High expression of long non-coding RNA MALAT1 in breast cancer is associated with poor relapse-free survival. Breast Cancer Res Treat. (2018) 171:261-71. doi: 10.1007/s10549-018-4839-2

99. Ren D, Zheng H, Fei S, Zhao JL. MALAT1 induces osteosarcoma progression by targeting miR-206/CDK9 axis. J Cell Physiol. (2018) 234:9507. doi: $10.1002 /$ jcp. 26923

100. Huang JK, Ma L, Song WH, Lu BY, Huang YB, Dong HM, et al. MALAT1 promotes the proliferation and invasion of thyroid cancer cells via regulating the expression of IQGAP1. Biomed Pharmacother. (2016) 83:1-7. doi: 10.1016/j.biopha.2016.05.039

101. Chu YH, Hardin H, Schneider DF, Chen H, Lloyd RV. MicroRNA21 and long non-coding RNA MALAT1 are overexpressed markers in medullary thyroid carcinoma. Exp Mol Pathol. (2017) 103:229-36. doi: 10.1016/j.yexmp.2017.10.002

102. Huang JK, Ma L. LncRNA-MALAT1 promotes angiogenesis of thyroid cancer by modulating tumor-associated macrophage FGF2 protein secretion. J Cell Biochem. (2017) 118:4821-30. doi: 10.1002/jcb.26153 
103. Zhang R, Hardin H, Huang W, Chen J, Asioli S, Righi A, et al. MALAT1 long non-coding RNA expression in thyroid tissues: analysis by in situ hybridization and real-time PCR. Endocr Pathol. (2017) 28:7-12. doi: 10.1007/s12022-016-9453-4

104. Liu J, Dong H, Yang Y, Qian Y, Liu J, Li Z, et al. Upregulation of long noncoding RNA MALAT1 in papillary thyroid cancer and its diagnostic value. Future Oncol. (2018) 14:3015-22. doi: 10.2217/fon-2018-0416

105. Wen J, Chen L, Tian H, Li J, Zhang M, Cao Q, et al. Effect of MALAT1 polymorphisms on papillary thyroid cancer in a Chinese population. $J$ Cancer. (2019) 10:5714-21. doi: 10.7150/jca.28887

106. Xia S, Ji R, Zhan W. Long noncoding RNA papillary thyroid carcinoma susceptibility candidate 3 (PTCSC3) inhibits proliferation and invasion of glioma cells by suppressing the Wnt/beta-catenin signaling pathway. BMC Neurol. (2017) 17:30. doi: 10.1186/s12883-017-0813-6

107. Wang X, Lu X, Geng Z, Yang G, Shi Y. LncRNA PTCSC3/miR-574-5p governs cell proliferation and migration of papillary thyroid carcinoma via Wnt/beta-catenin signaling. J Cell Biochem. (2017) 118:4745-52. doi: $10.1002 /$ jcb. 26142

108. Qi P, Zhou X-y, Du X. Circulating long non-coding RNAs in cancer: current status and future perspectives. Mol Cancer. (2016) 15:39. doi: 10.1186/s12943-016-0524-4

109. Shi T, Gao G, Cao Y. Long noncoding RNAs as novel biomarkers have a promising future in cancer diagnostics. Dis Mark. (2016) 2016:9085195. doi: $10.1155 / 2016 / 9085195$

110. Zhou X, Yin C, Dang Y, Ye F, Zhang G. Identification of the long non-coding RNA H19 in plasma as a novel biomarker for diagnosis of gastric cancer. Sci Rep. (2015) 5:11516. doi: 10.1038/srep11516

111. Tang H, Wu Z, Zhang J, Su B. Salivary lncRNA as a potential marker for oral squamous cell carcinoma diagnosis. Mol Med Rep. (2013) 7:761-6. doi: $10.3892 / \mathrm{mmr} .2012 .1254$

112. He T, Wang H, Sun J, Wu J, Gong F, Li S, et al. Altered expression of DLG1AS1 distinguished papillary thyroid carcinoma from benign thyroid nodules. BMC Endocr Disord. (2019) 19:122. doi: 10.1186/s12902-019-0440-x

113. Qiu ZL, Shen CT, Sun ZK, Wei WJ, Zhang XY, Song HJ, et al. Circulating long non-coding RNAs act as biomarkers for predicting 131I uptake and mortality in papillary thyroid cancer patients with lung metastases. Cell Physiol Biochem. (2016) 40:1377-90. doi: 10.1159/000453190

114. Song B, Li R, Zuo Z, Tan J, Liu L, Ding D, et al. LncRNA ENST00000539653 acts as an oncogenic factor via MAPK signalling in papillary thyroid cancer. BMC Cancer. (2019) 19:297. doi: 10.1186/s12885-019-5533-4

115. Guo K, Chen L, Wang Y, Qian K, Zheng X, Sun W, et al. Long noncoding RNA RP11-547D24.1 regulates proliferation and migration in papillary thyroid carcinoma: Identification and validation of a novel long noncoding RNA through integrated analysis of TCGA database. Cancer Med. (2019) 8:3105-19. doi: 10.1002/cam4.2150

116. Kim D, Lee WK, Jeong S, Seol MY, Kim H, Kim KS, et al. Upregulation of long noncoding RNA LOC100507661 promotes tumor aggressiveness in thyroid cancer. Mol Cell Endocrinol. (2016) 431:36-45. doi: 10.1016/j.mce.2016.05.002

117. Pritchard CC, Kroh E, Wood B, Arroyo JD, Dougherty KJ, Miyaji $\mathrm{MM}$, et al. Blood cell origin of circulating microRNAs: a cautionary note for cancer biomarker studies. Cancer Prev Res. (2012) 5:492-7. doi: 10.1158/1940-6207.CAPR-11-0370
118. Dobosy JR, Fu VX, Desotelle JA, Srinivasan R, Kenowski ML, Almassi $\mathrm{N}$, et al. A methyl-deficient diet modifies histone methylation and alters Igf2 and H19 repression in the prostate. Prostate. (2008) 68:1187-95. doi: 10.1002 /pros. 20782

119. Solanas M, Moral R, Garcia G, Grau L, Vela E, Escrich R, et al. Differential expression of $\mathrm{H} 19$ and vitamin D3 upregulated protein 1 as a mechanism of the modulatory effects of high virgin olive oil and high corn oil diets on experimental mammary tumours. Eur J Cancer Prev. (2009) 18:153-61. doi: 10.1097/CEJ.0b013e3283 136308

120. Agrawal N, Akbani R, Aksoy BA, Ally A, Arachchi H, Asa SL, et al. Integrated genomic characterization of papillary thyroid carcinoma. Cell. (2014) 159:676-90. doi: 10.1016/j.cell.2014. 09.050

121. Pita JM, Figueiredo IF, Moura MM, Leite V, Cavaco BM. Cell cycle deregulation and TP53 and RAS mutations are major events in poorly differentiated and undifferentiated thyroid carcinomas. J Clin Endocrinol Metab. (2014) 99:E497-507. doi: 10.1210/jc.2013-1512

122. Yoon H, He H, Nagy R, Davuluri R, Suster S, Schoenberg D, et al. Identification of a novel noncoding RNA gene, NAMA, that is downregulated in papillary thyroid carcinoma with BRAF mutation and associated with growth arrest. Int J Cancer. (2007) 121:767-75. doi: 10.1002/ijc. 22701

123. Wang Q, Yang H, Wu L, Yao J, Meng X, Jiang H, et al. Identification of specific long non-coding RNA expression: profile and analysis of association with clinicopathologic characteristics and BRAF mutation in papillary thyroid cancer. Thyroid. (2016) 26:1719-32. doi: 10.1089/thy.2016.0024

124. Esposito R, Esposito D, Pallante P, Fusco A, Ciccodicola A. Oncogenic properties of the antisense IncRNA COMET in BRAF- and RETdriven papillary thyroid carcinomas. Cancer Res. (2019) 79:2124-35. doi: 10.1158/0008-5472.CAN-18-2520

125. Rusinek D, Swierniak M, Chmielik E, Kowal M, Kowalska M, Cyplinska R, et al. BRAFV600E-Associated gene expression profile: early changes in the transcriptome, based on a transgenic mouse model of papillary thyroid carcinoma. PLOS ONE. (2015) 10:e0143688. doi: 10.1371/journal.pone.0143688

126. Kanasty R, Dorkin JR, Vegas A, Anderson D. Delivery materials for siRNA therapeutics. Nat Mater. (2013) 12:967-77. doi: 10.1038/nmat3765

127. Weidle UH, Birzele F, Kollmorgen G, Ruger R. Long non-coding RNAs and their role in metastasis. Cancer Genom Proteom. (2017) 14:143-60. doi: $10.21873 / \operatorname{cgp} .20027$

Conflict of Interest: The authors declare that the research was conducted in the absence of any commercial or financial relationships that could be construed as a potential conflict of interest.

Copyright (c) 2020 Peng, Zhang, Ma, Xu and Chang. This is an open-access article distributed under the terms of the Creative Commons Attribution License (CC BY). The use, distribution or reproduction in other forums is permitted, provided the original author(s) and the copyright owner(s) are credited and that the original publication in this journal is cited, in accordance with accepted academic practice. No use, distribution or reproduction is permitted which does not comply with these terms. 